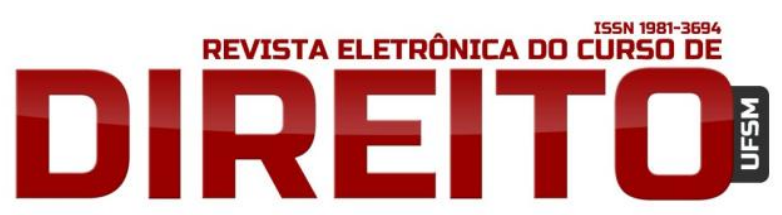

\title{
REFUGIADOS AMBIENTAIS E A ATUAÇÃO DO ACNUR COMO ORGANISMO INTERNACIONAL DE PROTEÇÃO
}

\author{
ENVIRONMENTAL REFUGEES AND THE ACTION OF UNHCR AS AN \\ INTERNATIONAL PROTECTION ORGANISM
}

\author{
MARIA DE LAS MERCEDES RODRÍGUEZ FONTÁN LUCHINO \\ Doutoranda da Faculdade de Direito da Universidad Nacional de La Plata, Buenos Aires, Argentina.
} mercedesrf02@hotmail.com

WAGNER COSTA RIBEIRO

Doutor em Geografia da Universidade de São Paulo (USP) e Professor Titular do Departamento da Geografia da USP.

São Paulo, SP, Brasil.

wribeiro@usp.br

\begin{abstract}
RESUMO
Atualmente, na ordem internacional, verifica-se o surgimento dos refugiados ambientais ou deslocados ambientais forçados. 0 refugiado ambiental ou deslocado ambiental forçado é aquele que é obrigado a deixar seu lugar de moradia devido a um desastre ambiental ou degradação ambiental, que colocam sua vida em perigo, ou que não permitem assegurar sua sobrevivência. Eles estão desprotegidos no Direito Internacional, verificando-se uma lacuna normativa. 0 objetivo deste trabalho é analisar as possibilidades de que seja designada a ACNUR como uma agência internacional para proteger os refugiados ambientais ou deslocados ambientais forçados. Os procedimentos metodológicos utilizados são a pesquisa bibliográfica, documental e instrumentos internacionais. Em primeiro lugar, conceitua-se os deslocados ambientais forçados ou refugiados ambientais. Em segundo lugar, analisa-se a posição adotada por ACNUR em relação a esses afetados, desde 2007. Finalmente, apresentamse as observações finais.
\end{abstract}

Palavras-chave: ACNUR; Deslocados ambientais forçados; Lacuna normativa; Refugiados ambientais.

\begin{abstract}
Currently, in the international order, it can be seen the emergence of environmental refugees or environmentally displaced people. The environmental refugee or environmentally displaced is the one who is forced to leave his living place due to an environmental disaster or degradation, which put their life in danger, or that do not allow to ensure their survival. They are unprotected by International Law, showing a regulatory gap. The objective of this study is to analyze the possibilities of nominating UNHCR as an international agency to protect environmental refugees or environmentally displaced people. The methodological procedures used are bibliographical and documentary research and international instruments. First, it presents the concepts of environmentally displaced people or environmental refugees. Secondly, it analyzes the position adopted by UNHCR in relation to those affected, since 2007. At last, it makes final observations.
\end{abstract}

Keywords: UNHCR; Environmentally displacement people; Regulatory gap; Environmental refugees. 




\section{SUMÁRIO}

INTRODUÇÃO; 1 REFUGIADOS AMBIENTAIS OU DESLOCADOS AMBIENTAIS FORÇADOS; 2 ACNUR E OS DESLOCADOS AMBIENTAIS FORÇADOS TRANSFRONTEIRIÇOS DE 2007 A 2012; 2.1 O ACNUR e OS Deslocamentos Ambientais Forçados de 2007 a 2010; 2.2 A situação do ACNUR no ano de 2011; 2.2.1 Reunião Bellagio e Conferência Nansen; 2.2.2 O plano piloto do IASC para que o ACNUR fosse o líder na proteção dos Deslocados Ambientais Forçados; 3 OBSERVAÇõES SOBRE O ACNUR DE 2013 A OUTUBRO DE 2015; CONCLUSÃO; REFERÊNCIAS.

\section{INTRODUÇÃO}

Cada vez mais frequentes, as catástrofes ambientais afetam, antes de mais nada, as pessoas. Como resultado surgem perdas de vidas humanas. Outras pessoas são afetadas com perdas materiais de tal ordem que não conseguem mais viver em seus locais de origem. Sem alternativa, começam a deslocar-se forçadamente, muitas vezes alcançando até outros países.

No período entre 2008 e 2012 houve 142 milhões de deslocados pelos desastres ${ }^{1}$. A partir de dados mais recentes, se observa que no ano de 2014 verificaram-se 19.300.000 deslocados ambientais forçados ${ }^{2}$.

Segundo o International Displacement Monitoring Center, a análise do período de 2008 a 2013 demonstra uma média de 27 milhões de deslocados ambientais forçados por ano. Esse Relatório especifica a quantidade de refugiados ambientais correspondentes a cada um desses anos. Em 2013, foram 21.900.000 refugiados ambientais, em 2012, houve 32.400.000 de pessoas, em 2011, se verificaram 15.000.000, em 2010 foram 42.400.000, em 2009, foram 16.700.000 e em 2008, foram $36.500 .000^{3}$.

Essas cifras deixam em relevância a magnitude e a urgência do problema que aflige tanto aos países afetados como à comunidade internacional.

A primeira definição sobre refugiados ambientais foi a de Essam EL-HINNAWI, quem considerou que são aquelas pessoas obrigadas a abandonar seus lugares de origem porque os

\footnotetext{
${ }^{1}$ NANSEN INICIATIVA. Linking human mobility, disasters and disaster risk reduction. Outubre de 2014, p.1. Disponível em: <http://www.unhcr.org/5448c8269.html> Acesso em: jun. 2015.

2 INTERNAL DISPLACEMENT MONITORING CENTER. NORWEGIAN REFUGEE COUNCIL. People displaced by disasters. Global Estimatives 2015. 2015, p.19.

3 INTERNAL DISPLACEMENT MONITORING CENTER. NORWEGIAN REFUGEE COUNCIL. People displaced by disasters. Global Estimatives 2014. 2014, p. 1.
} 
desastres colocam suas vidas em perigo. Tais catástrofes podem ser causadas pela natureza, pela sociedade ou por ambos ${ }^{4}$.

Essas pessoas que são forçadas a deslocarem-se para outros lugares. Na maioria das vezes, o destino não é escolhido por elas, que chegam a eles aleatoriamente.

0 desastre ambiental arrasa tudo o que encontra por seu caminho, começando pela vida das pessoas que não conseguem escapar, perdas de moradias, roupas, meios de subsistência, alimentos, água potável, surgimento de doenças, famílias destruídas ou divididas. Por causa do desastre ou degradação ambiental, esses seres humanos têm que deixar seus locais de origem, seus lares, seus povos, e seus meios de trabalho habituais, sendo despojados de tudo aquilo que era necessário para sua vida digna como suas casas, suas roupas, suas propriedades, seus povos, suas tradições e a sua cultura.

Os refugiados ambientais têm violados seus direitos fundamentais como o direito à vida, à segurança, à liberdade, à igualdade, aos direitos correspondentes às necessidades mínimas tais como alimento, moradia, roupa, saúde, educação, trabalho, religião, cultura, documentação pessoal, as suas propriedades e bens, ao ser cultural do povo. Em outras palavras, são pessoas que perdem a dignidade.

IASC reconhece essas violações dos direitos humanos dos deslocados ambientais dos desastres naturais ${ }^{5}$. 0 problema dos deslocados ambientais forçados é de natureza internacional, pois o tipo de catástrofe ambiental que os aflige não respeita fronteiras, e em muitos casos abarca vários países. Trata-se de mais um dos elementos da ordem ambiental internacional ${ }^{6}$.

É necessário observar que existem alguns refugiados ambientais que escapam para outros países, por isso podem ser chamados de "externos". No entanto, outros conseguem chegar a lugares menos distantes do desastre dentro do pais, quando são chamados de deslocados internos.

A principal diferença entre os deslocados ambientais forçados internos e "externos" é o fato de que os últimos atravessarem a fronteira política de um país. Mas os primeiros têm um marco de proteção no direito internacional: os Princípios Reitores dos Deslocados Internos. Esta

\footnotetext{
${ }^{4}$ EL-HINNAWI, Essam. Environmental Refugees. Nairobi, Kenya: United Nations Environment Programme, 1985, p. 4.

${ }^{5}$ IASC. Directrices operacionales del IASC sobre la protección de las personas en situaciones de desastres naturales. Proyecto de Brookings - Bern sobre Desplazamiento Interno. Mayo de 2011. Disponível em: <http://www.hewsweb.org/floods/flood.asp?FID=198379> Acesso em: 20 jul. 2014.

${ }^{6}$ RIBEIRO, Wagner Costa. A ordem ambiental internacional. São Paulo: Contexto, 2001, p.22.

${ }^{7}$ A Conferência Nansen denomina aqueles que se deslocam fora do pais como "externos", em oposição àqueles que são deslocados dentro do pais.
} 
regulamentação internacional surgiu de uma Resolução da Assembleia Geral das Nações Unidas, de 1998. Antes disso, houve outras resoluções do mesmo organismo das Nações Unidas, a Resolução da Assembleia Geral 47/105 de 1993, a Resolução da Assembleia Geral 48/116 de 1994 e a Resolução da Assembleia Geral 49/169 de 1995, as que estabeleceram que o Alto Comissariado das Nações Unidas para os Refugiados (ACNUR) é quem se encarrega dos deslocados internos.

A situação do refugiado ambiental "externo" não tem uma regulação no sistema universal do direito internacional que thes brinde o amparo necessário de seus direitos. Essa lacuna deixa em evidencia a complexidade da problemática dos refugiados ambientais ou deslocados ambientais forçados “externos” que têm falta de um regime global para proteção, assim como ausência de um organismo internacional que assuma a responsabilidade de garantir suas condições de vida.

Essa reflexão vai tratar dos refugiados ambientais transnacionais, bem como analisar a possibilidade de atuação do ACNUR junto a eles. Isso decorre do fato de que, em 2007, o ACNUR abandonou sua posição de neutralidade diante dos deslocamentos ambientais forçados. Com o transcurso dos anos, este organismo internacional expressou interesse em assumir para si o papel de líder na proteção de todos os deslocados dos desastres naturais.

O objetivo deste trabalho é analisar a atuação do ACNUR em relação à questão dos deslocados ambientais forçados entre os anos de 2007 e 2014.

No enfrentamento teórico e conceitual dessa temática, deparou-se com uma escassez de produção doutrinária, nacional e internacional, sobre o ACNUR como órgão encarregado de assumir a competência para proteger os deslocados ambientais forçados transnacionais. Diante dessa situação, optou-se por trabalhar documentos dos organismos das Nações Unidas, principalmente.

Em primeiro lugar, apresenta-se o conceito dos deslocados ambientais forçados ou refugiados ambientais. Em segundo lugar, serão consideradas as posições doutrinarias sobre o organismo que precisa assumir a responsabilidade de proteger aos refugiados ambientais. Em terceiro lugar, será considerada a posição adotada no seio do ACNUR em relação aos deslocados ambientais forçados desde 2007 até 2014. E, em quarto lugar, serão realizadas as considerações finais sobre o assunto. 




\section{REFUGIADOS AMBIENTAIS OU DESLOCADOS AMBIENTAIS FORÇADOS}

Muitos autores thes chamam de refugiados ambientais, outros de refugiados climáticos, embora o ACNUR não recomende o uso dessas denominações devido a que podem levar a uma assimilação com os refugiados definidos pela Convenção sobre o Estatuto dos Refugiados de 1951.

O direito internacional protege os deslocados ambientais forçados internos, deixando os que atravessam as fronteiras de seus países à deriva. Neste trabalho não se distingue entre os que atravessam uma fronteira ou se deslocam dentro de seu país, porque esta diferenciação depende dos recursos econômicos de cada um dos afetados. Os mais pobres não conseguem atravessar fronteiras. A trajetória de viagem não resulta da vontade de permanecer ou ir, mas depende dos recursos financeiros e saúde também, visto que idosos e crianças são as vítimas mais frequentes por não suportarem o esforço físico do deslocamento.

Uns autores consideram a causa do desastre ou degradação ambiental, restringindo o conceito a aqueles que são obrigados a deslocar-se por causa das Mudanças Climáticas que originaram os impactos. A denominação dada a essas pessoas afetadas é "Refugiados Climáticos ou "Refugiados das Mudanças Climáticas" ${ }^{8}$. Outra parte da doutrina considera o desastre ou a degradação ambiental que obriga a essas pessoas a escapar com indiferença da causa que a originou. Esses são denominados de "refugiados ambientais"?.

A definição adotada nesse texto não considera as causas dos desastres ou degradação que produzem o deslocamento, mas sim os cenários. Outros autores consideram a diferenciação entre se essas pessoas se deslocam dentro do país ${ }^{10}$ ou atravessam as fronteiras ${ }^{11}$.

Outro critério para distinguir-lhes é se são deslocados permanentes ou temporários. Os deslocados permanentes são aqueles que estão em pior situação porque seus lugares de origem

\footnotetext{
${ }^{8}$ BIERMANN, Frank; BOAS, Ingrid. Preparing for a Warmer World: Towards a Global Governance System to Protect Climate Refugees, 10 GLOBAL ENVIRONMENTAL POLITICS, Amnsterdam, 2007, p. 8. Disponível em:<http://www.environmentalmigration.iom.int/preparing-warmer-world-towards-global-governancesystem-protect-climate-refugees> Acesso em: 15 fev. 2014.

9 WARNER, Koko. Environmental Change and Migration: Issues for European governance and migration management, p. 1. In Network Migration In Europe E.V. Disponível em: <www.migrationeducation.org> Acesso em: 20 mar. 2014.

${ }^{10}$ IASC. Directrices operacionales del IASC sobre la protección de las personas en situaciones de desastres naturales. Proyecto de Brookings - Bern sobre Desplazamiento Interno. Maio de 2011. Disponível em: <http:/ / www.hewsweb.org/floods/flood.asp?FID=198379> Acesso em: 20 jun. 2014.

${ }^{11}$ DOCHERTY, Bonnie; GIANNINI, Tyler. Confronting a Rising Tide: A Proposal for a Convention on Climate Change Refugees, 33 Harv. Envtl. L. Rev. 344, 2009. Disponível em: <http://lawlib.wlu.edu/CLJC/index.aspx?mainid=244\&issuedate=2009-07-30>. Acesso em: 25 mai. 2014.
} 
desapareceram (submersão de uma ilha ou regiões costeiras de terras de baixa altitude). Os temporários são aqueles que puderam retornar a seus locais de origem depois que terminou o risco para a vida.

Outros autores consideram como refugiados ambientais àqueles que são voluntários e forçados $^{12}$. No entanto, nesse trabalho somente se consideram os forçados, porque os voluntários poderiam ser assimilados aos migrantes.

Por isso, é fundamental a construção de um conceito unificador do deslocado ambiental forçado. A denominação escolhida neste trabalho é a de "Deslocados Ambientais Forçados" ou Refugiados Ambientais, porque todos os aspectos essenciais destes afetados são abrangidos nessa designação.

A definição dos Deslocados Ambientais Forçados que foi adotada para os objetivos deste trabalho é:

Aquele que é obrigado a deixar seu lugar de moradia devido a um desastre ambiental ou degradação ambiental, que colocam sua vida em perigo, ou que não permitem assegurar sua sobrevivência, produzindo-se a violação dos Direitos Humanos, sendo necessário que se aplique o Princípio de Assistência à Vítima, e que, por toda essa situação, é obrigado a se deslocar para outro lugar dentro ou fora de seu país, e que não pode ser obrigado a retornar a seu lugar de origem enquanto durem as ameaças a seus Direitos Humanos ${ }^{13}$.

Este conceito permite compreender que essas pessoas, sejam elas deslocadas "internas" ou "externas", que sofrem as violações aos Direitos Humanos em geral, e especificamente o direito à liberdade de escolha do lugar para residir, pois não importa se eles preferem permanecer ou sair de seus lugares de origem. Estes dois últimos aspectos os convertem em deslocados forçados porque a violência do desastre ou da degradação impede o exercício da liberdade de escolher, dada a magnitude da violação ao direito à vida, aos alimentos, à água, à saúde, às roupas, ao refúgio, à liberdade e à igualdade ${ }^{14}$.

\footnotetext{
12 HODGKINSON, David; YOUNG, Lucy. In the face of looming catastrophe: a Convention for Climate Change Displaced Persons, 2009, p. 7. Disponível em: <http://www.ccdpconvention.com/documents/ A\%20Convention\%20for\%20Climate\%20Change\%20Displaced\%20Persons\%20\%28January\%202012\%29.pdf > Acesso em: 20 feb. 2014.

${ }^{13}$ RODRIGUEZ FONTÁN LUCHINO, María de las Mercedes. La Pérdida del territorio de los Pequeños Estados Insulares. In: Anais do XI Encontro Nacional da Anpege: A diversidade da Geografia Brasileira -Escalas e dimensões da análise e da ação. Presidente Prudente: ANPEGE-UNESP, 2015.

14 RODRIGUEZ FONTÁN LUCHINO, María de las Mercedes. Los Desplazados Ambientales Forzados y la violación de sus derechos humanos. In: Anales del II Congreso Internacional SETED-Ante, Universidad de Santiago de Compostela. España, 2015.
} 




REFUGIADOS AMBIENTAIS E A ATUAÇÃO DO ACNUR COMO ORGANISMO INTERNACIONAL DE PROTEÇÃO

MARIA DE LAS MERCEDES RODRÍGUEZ FONTÁN LUCHINO WAGNER COSTA RIBEIRO

Outro aspecto relevante deste conceito é que o que se considera é o desastre ou a degradação ambiental e seus cenários de deslocação forçada, sem fazer diferenciação se foram provocados pelas mudanças climáticas ou por outros tipos de causas.

Por outro lado, é parte integrante da definição a necessária aplicação do princípio de Não Devolução, o que implica que as pessoas não podem ser obrigadas a voltar aos lugares onde subsistem os perigos, porque os impactos do desastre ou da degradação colocam em perigo a vida ou sobrevivência dessas pessoas.

O princípio de Não Devolução teve origem na Convenção sobre Refugiados de 1933, embora esse Instrumento Internacional nunca entrou em vigência devido à falta de ratificações dos países. Posteriormente, foi incorporado à Convenção sobre o Estatuto dos Refugiados de 1951, que considera que os refugiados políticos não poderão ser obrigados a voltar a seus países, no entanto continuem as persecuções do Estado, ou em quanto não desejam voltar. 0 direito a retornar ao lugar de origem dos refugiados ambientais somente pode ser voluntário, nunca forçado.

Docherty e Giannini ampliam esse conceito do princípio, considerando que a ameaça pode ser causada por uma mudança climática ${ }^{15}$.

O princípio de Assistência à Vítima foi consagrado no Direito Internacional em 2008, na Convenção de Cluster Munition. Ela estabeleceu que era preciso brindar às vítimas assistência médica e psicológica, inclusão social e econômica. Esses autores consideram que esse princípio poderia ser aplicado aos refugiados ambientais, mas observam que caso isso ocorresse, teria outro conteúdo. O conteúdo desse princípio seria brindar a ajuda no referente a alimentos, água, roupas, refugio e saúde ${ }^{16}$.

A necessidade da aplicação aos refugiados ambientais do princípio de Assistência à Vítima é fundamental, pois permite verificar se essas pessoas são forçadas, pois desse modo, pode verificar-se a violação a seus direitos humanos e se precisam receber a ajuda internacional.

\footnotetext{
${ }^{15}$ DOCHERTY, Bonnie; GIANNINI, Tyler. Confronting a Rising Tide: A Proposal for a Convention on Climate Change Refugees. 33 Harv. Envtl. L. Rev. p. 344, 2009. Disponível em: <http:/ / lawlib.wlu.edu/CLJC/index.aspx?mainid=244\&issuedate=2009-07-30> Acesso em: 25 maio 2014.

${ }^{16}$ DOCHERTY, Bonnie; GIANNINI, Tyler. Op. Cit., 33 Harv. Envtl. L. Rev. p. 378, 2009.
} 


\section{(1)

\section{REFUGIADOS AMBIENTAIS E O ORGANISMO DE PROTEÇÃO: ACNUR}

Nesse item serão consideradas declarações, as atividades e as publicações realizadas pelo ACNUR em relação à sua vontade de assumir a responsabilidade pelos deslocados ambientais forçados. Elas foram divididas em momentos relevantes do período.

\subsection{ACNUR e os Deslocamentos Ambientais Forçados de 2007 a 2010}

Nina HALL observa que, desde 2007, o ACNUR foi modificando sua atitude em relação aos deslocamentos ambientais forçados, sendo que até aquele ano, ACNUR não havia demonstrado nenhum tipo de interesse no problema dos deslocados ambientais forçados. Nesse sentido, são enunciados os fatos mais importantes realizados pelo ACNUR de 2007 a 2011. Em primeiro lugar, em 2007, o Alto Comissariado começou a fazer diversas manifestações de sua preocupação sobre a incidência das cinco megatendências sobre os deslocamentos, sendo que uma destas consistia nas Mudanças Climáticas. Em segundo lugar, em 2008, todas as Agências das Nações Unidas foram instadas a trabalhar sobre a relação das mudanças climáticas e os deslocamentos, a pedido do Secretário Geral das Nações Unidas. Em resposta, o ACNUR criou um grupo de trabalho para analisar a questão. Por outro lado, nesse mesmo ano, o IASC $^{17}$ instou o Alto Comissariado a participar de um grupo de Agências Internacionais para desenvolver esse trabalho. Além disso, durante 2008, o ACNUR apresentou sua publicação “Climate Change, Natural Disasters and Human Displacement: a UNHCR Perspective", que posteriormente será analisada. Em 2009, esse organismo participou na Conferencia Marco de Nações Unidas sobre Mudanças Climáticas (UNFCCC). ${ }^{18}$

Pode-se constatar que, a partir de 2007, produz-se uma mudança que significa uma ruptura com a posição do ACNUR observada anteriormente em relação à questão. Essa mudança foi impulsionada pelo Alto Comissariado Guterres, quem, por meio de suas declarações demonstrou a importância e a urgência no tratamento da questão dos deslocamentos provocados

17 O IASC é o Comitê Permanente de Interagências das Nações Unidas que faz frente às Emergências dos Desastres Naturais e Emergências Complexas, ainda que somente se ocupe dos deslocados internos dos desastres naturais, deixando de lado, os deslocados dos desastres naturais transfronteiriços, aos quais ninguém oferece proteção.

${ }^{18}$ HALL, Nina. Moving beyond Its Mandate? UNHCR and Climate Change Displacement. 4 J. of Int'l Orgs Studies, 2013, p. 91. 
pelas mudanças climáticas. A seguir, serão considerados de forma específica alguns dos principais eventos nesse sentido.

Para Guterres as cinco megatendências que influenciariam o deslocamento forçado das pessoas eram: “o aumento da população, a urbanização, a insegurança alimentar e energética, a escassez de água e a mudança climática”.

Há uma observação muito interessante de Guterres que considera:

[...] que o deslocamento causado pelos efeitos da evolução lenta da mudança climática é em grande parte interno. Mas, através da aceleração da seca, da desertificação, da salinização das águas subterrâneas e do solo, e do aumento do nível do mar, a mudança climática, também, pode contribuir ao deslocamento de pessoas através de fronteiras internacionais. ${ }^{19}$

Desse modo, pode-se observar que especificamente no caso dos desastres produzidos por processos de lenta evolução, os deslocamentos são dentro do país, mas quando se agravam, a trajetória da viagem dos deslocados aumenta, chegando a ser através das fronteiras. Outra peculiaridade deste tipo de desastre é que nos primeiros momentos, os deslocamentos são voluntários e na medida em que se agrava a situação do desastre, as pessoas se veem obrigadas a escapar para outros lugares, onde possam sobreviver. Um dos exemplos deste tipo de desastre é a submersão de uma ilha, de uma região costeira, como foi o caso dos Inuits ${ }^{20}$, cujo lugar de sobrevivência desapareceu por causa do derretimento das calotas de gelo do polo norte.

A produção do desastre nestes casos é gradual, da mesma maneira que o processo do deslocamento de pessoas se produz nesse sentido.

No ano de 2008, o ACNUR apresentou uma publicação chamada "Climate Change, Natural Disasters and Human Displacement: a UNHCR perpective", já mencionada anteriormente, e que será analisado a seguir. Nesse estudo, se manifesta sua preocupação pela magnitude do problema dos deslocamentos ambientais forçados e considera a atuação desse organismo em cada um dos cenários de desastre ou degradação apresentados por KÄLIN.

KÄLIN e SCHREPFER consideram especificamente os cenários dos deslocamentos ambientais forçados, a saber:

\footnotetext{
${ }^{19}$ UNITED NATIONS HIGH COMMISSIONER FOR REFUGEES, EXECUTIVE COMMITTEE. Questions and answers on UNHCR's Protection Cluster Coordination role in natural disasters, p.1. fev. de 2011.

${ }^{20}$ CLARKE, Meghan Elisabeth. Climate Change and Human Rights: A Case Study of the Canadian Inuit and Global Warming in the Canadian Arctic. A thesis submitted in conformity with the requirements for the degree of Master of Laws (LLM). Graduate Department of the Faculty of Law University of Toronto, Toronto, 2010, p. 62. Disponível em: <https://tspace.library.utoronto.ca/bitstream/1807/25457/1/Clarke _Meghan_E_201011_LLM_thesis.pdf> Acesso em: 10 jul. 2014.
} 
1. Desastres Repentinos, tais como inundações, tempestades de vento (furacões/tufões/ciclones) ou deslizamentos de terra causados por fortes chuvas podem provocar grandes deslocamentos: as pessoas são evacuadas ou deixam seus lares antes dos desastres ou precisam deixar seus lares devido à destruição de suas casas, infraestrutura e serviços. [...]

2. Processos de Lenta Degradação Ambiental causados pelo aumento do nível do mar, aumento de salinização dos solos, efeitos de longa duração derivados de recorrentes inundações, desgelo das calotas do Polo Norte, assim como as secas e a desertificação e outras formas de redução dos recursos hídricos, são previstos como impactos negativos em longo prazo da mudança climática. [...]

3. Os Pequenos Estados Insulares com terras baixas representam um caso especial dos desastres de evolução lenta. Como consequência do aumento do nível do mar e de sua topografia de baixa altitude, estas áreas podem se tornar cada vez mais inabitáveis, o que provoca a emigração a outros países, as pessoas perdem a fé de que haja um futuro para elas em sua terra natal. A degradação ambiental será um processo muito lento [...]

4. Como consequência da mudança climática, os governos designam áreas proibidas de serem habitadas por pessoas. [...]

5. Por último, os sérios distúrbios da ordem pública, a violência ou inclusive conflitos armados que perturbam gravemente, podem ser provocados, ao menos parcialmente, pela diminuição dos recursos essenciais devido à mudança climática (como a água, as terras de cultivo ou pastos) [... ${ }^{21}$

Em relação ao primeiro cenário, é necessário observar que o desastre é abrupto, e de uma magnitude suficiente para obrigar as pessoas a abandonar seus lares, deixando-as em uma situação de emergência absoluta, com a única esperança de sobreviver.

A segunda e a terceira situações enunciadas por Kälin e Schrepfer consistem em processos lentos de degradação ou desastre, onde podem se verificar dois momentos, o primeiro consiste em que as pessoas ou grupos de pessoas escapam preventivamente, o segundo é quando as pessoas são forçadas a abandonar seus habitats para poder sobreviver.

O quarto cenário dos deslocados ambientais forçados poderia ser apreciado à luz do direito dos apátridas, pois o aumento do nível do mar produzirá a perda do território desses países insulares. 0 quinto cenário é aquele que se configura pelos conflitos derivados da luta pela falta de recursos desencadeada pelas mudanças climáticas. Os deslocados ambientais forçados surgidos neste último caso poderiam ser considerados como "refugiados" segundo leis complementares $^{22}$ do ACNUR. ${ }^{23}$

${ }^{21}$ KÄLIN, Walter y SCHREPFER. Protecting People Crossing Borders in the Context of Climate Change Normative Gaps and Possible Approaches. University of Bern, UNHCR, Switzerland, 2012, p. 13 a 16. Disponível em: <http://www.unhcr.org/4f33f1729.pdf >. Acesso em: jan. 2014.

${ }_{22}$ As Leis Complementares do ACNUR são as Resoluções da Assembleia Geral das Nações Unidas.

${ }^{23}$ UNHCR. Climate change, natural disasters and human displacement: a UNHCR perspective. UNHCR, Genebra, October, 2008, p. 5. Disponível em: <http://www.unhcr.org/4901e81a4.html>. Acesso em: 10 jan. 2014. 
Em novembro de 2009, Guterres reiterou sua preocupação de que as mudanças climáticas produziriam o aumento no número de desastres naturais, tendo como consequência os deslocamentos massivos que poderiam ser internos ou através das fronteiras. No caso dos internos, a responsabilidade principal é do Estado nacional, que tem a obrigação de oferecer proteção a seus habitantes. Na segunda situação, a daqueles que vão para o estrangeiro, não existe nenhuma proteção internacional. ${ }^{24}$

Em 2010, o ACNUR apresentou outra publicação, "Earth, wind and fire. A review of UNHCR"s role in recent natural disasters", onde sustentou que era necessário que fosse estabelecida a sua participação nos casos dos migrantes forçados da mudança climática. É importante observar a crítica ao IASC:

Em geral, se reconhece que os arranjos existentes para a designação do organismo Coordenador-Líder do Grupo de Proteção em nível de país para responder aos desastres naturais tal como previsto em 2006 pelo Comitê Permanente entre Organismos (IASC) através da Nota de Orientação sobre o uso do Enfoque do Grupo para o Fortalecimento da Resposta Humanitária demonstraram ser disfuncionais. ${ }^{25}$

O IASC organizou, em 2008, um grupo de trabalho sobre as Mudanças Climáticas e os Deslocamentos, no qual participaram o ACNUR e a Organização Internacional da Migração (OIM). 0 resultado desse trabalho seria apresentado nas negociações da Convenção-Quadro das Nações Unidas sobre Mudança do Clima (UNFCCC) realizadas em Cancun em 2010. Em relação a isso, Mc Adam observa que:

O ACNUR e a OIM foram fundamentais na defesa dos deslocamentos através das fronteiras abordados neste contexto [...]. Em dezembro de 2010, a Conferência sobre as Mudanças Climáticas da ONU (COP16) adotou o Quadro de Adaptação de Cancun, que foi o resultado de três anos de negociações sobre a adaptação pelos Estados Partes na UNFCCC. ${ }^{26}$

Desse modo, em dezembro de 2010, nesta Conferência foi reconhecido o aspecto humano dos impactos das Mudanças Climáticas. Isto consta no parágrafo 14, (f), do Acordo:

\footnotetext{
${ }^{24}$ GUTERRES, António. Five 'mega-trends'-including population growth, urbanization, climate changemake contemporary displacement increasingly complex, third committee told. Third Committee, General Assembly GA/SHC/3964. New York: United Nations, 3 November 2009. Disponivel em: <http://www.un.org/press/en/2009/gashc3964.doc.htm> Acesso em: 2 jan. 2014.

${ }^{25}$ UNITED NATIONS HIGH COMMISSIONER FOR REFUGEES. POLICY DEVELOPMENT AND EVALUATION SERVICE (PDES). Earth, wind and fire. A review of UNHCR"s role in recent natural disasters. Bryan Deschamp, Consultant. Michelle Azorbo, PDES. Sebastian Lohse, Consultant. PDES, June 2010, p. 1.

${ }^{26}$ MC ADAM, Jane. Creating New Norms on Climate Change, Natural Disasters and Displacement: International Developments 2010-2013. Refuge, Vol 29, No 2 , 2014, Disponível em: <http://www.unhcr.org/542e9a509.pdf > Acesso em: jun. 2015.
} 
14. Convida todas as Partes para melhorar as medidas de adaptação sob o Quadro de Adaptação de Cancun, tendo em conta suas responsabilidades comuns, mas diferenciadas, e respectivas capacidades, e prioridades de desenvolvimento nacionais e regionais, os objetivos e as circunstâncias empreendidas, entre outras coisas, o seguinte:

[...]

(f) Medidas para melhorar a compreensão, a coordenação e a cooperação com respeito ao deslocamento induzido pela mudança climática, a migração e a realocação planificada, onde proceda, nos planos nacional, regional e internacional; ${ }^{27}$

Este parágrafo é muito importante porque constitui o primeiro reconhecimento no nível internacional da problemática dos deslocados ambientais forçados, embora somente se refira àqueles que resultam das mudanças climáticas. Em segundo lugar, este dispositivo tornaria possível a utilização do Fundo de Financiamento Verde para o Clima, pois considera estes tipos de deslocamentos como medidas de adaptação. Por outro lado, cabe destacar que essa normativa levou a que essa problemática fosse colocada na agenda internacional. ${ }^{28}$

\subsection{A situação do ACNUR no ano de 2011}

\subsubsection{Reunião Bellagio e Conferência Nansen}

O ano de 2011 foi muito especial e cheio de expectativas para o Alto Comissariado devido a que se comemorava o $60^{\circ}$ aniversário da Convenção sobre o Estatuto dos Refugiados, e se esperava a atribuição do ACNUR como o organismo encarregado da proteção dos deslocados ambientais forçados "externos".

Dessa forma, no mês de fevereiro de 2011, o ACNUR organizou uma Reunião de Expertos levada a cabo em Bellagio, onde o principal objetivo era constatar a falta de regulamentação para o problema dos Deslocados Ambientais Forçados que atravessam as fronteiras, assim como alcançar o apoio para que o ACNUR fosse designado como o organismo internacional capaz de

${ }^{27}$ COP (CANCUN). Decision 1/CP.16, The Cancun Agreements: Outcome of the work of the Ad Hoc Working Group on Long-Term Cooperative Action under the Convention, in Report of the Conference of the Parties on its sixteenth session, Addendum, Part Two: Action taken by the Conference of the Parties, FCCC/CP/2010/7/Add.1, 15 mar. 2011, parágrafo 14 (f).

${ }^{28}$ KALIN, Walter. From the Nansen Principles to the Nansen Initiative. FMR 41, December 2012, p. 48. Disponível em: <http://www.fmreview.org/preventing/kalin> Acesso em: 15 jan. 2014. 
oferecer-lhes proteção e assistência. Esse encontro foi rico no aporte de novas perspectivas e considerações para a situação. ${ }^{29}$

Uma das recomendações mais importantes das que surgiram na Reunião de Bellagio foi a seguinte:

Existe uma necessidade de desenvolver um quadro de referência global ou um instrumento que se aplique às situações de deslocamento externo distinto do contemplado na Convenção de 1951, especialmente para o deslocamento resultante dos desastres repentinos. Os Estados, junto com o ACNUR e outras organizações internacionais, são animados a explorar mais a fundo. Considerações seriam necessárias para brindar esse marco ou instrumento que deveria abranger essas outras formas de deslocamento externo contemporâneas. ${ }^{30}$

Além disso, foi ressaltada a importância do papel da ciência nestes processos de deslocamentos forçados ambientais, dada a complexidade que emerge tanto das Mudanças Climáticas, as que são uma das causas que motivam os desastres e os processos de degradação. ${ }^{31}$

$\mathrm{Na}$ ordem ambiental internacional a ciência, com frequência, é usada para estabelecer uma regulação, um procedimento e até uma norma. ${ }^{32}$ Cabe à ciência não ser neutra, mas sim estabelecer parâmetros em prol dos direitos humanos. Porém nem sempre isso ocorre, muitas vezes ela é instrumentalizada para interesses particulares.

$\mathrm{Na}$ Reunião de Especialistas de Bellagio foram consideradas que as respostas a essas situações deviam estar fundadas nos princípios de "Humanidade, Dignidade, Direito Humanos, Cooperação Internacional, Consentimento, Participação e preocupação pelos grupos vulneráveis." 33

$\mathrm{Na}$ realidade, os princípios de Humanidade, Dignidade e Direitos Humanos estão interrelacionados, pois os "Direitos Humanos" são aqueles direitos mínimos que devem ser assegurados a todos as pessoas para que possam ter uma vida "digna". A dignidade é a finalidade da busca da eficácia universal dos Direitos Humanos.

\footnotetext{
${ }^{29}$ UNITED NATIONS HIGH COMMISSIONER FOR REFUGEES, EXECUTIVE COMMITTEE. Questions and answers on UNHCR's Protection Cluster Coordination role in natural disasters. Fevereiro de 2011.

${ }^{30}$ UNITED NATIONS HIGH COMMISSIONER FOR REFUGEES, EXECUTIVE COMMITTEE. Op. Cit., p. 1. Fevereiro de 2011.

${ }^{31}$ UNITED NATIONS HIGH COMMISSIONER FOR REFUGEES, EXECUTIVE COMMITTEE. Op. Cit., p. 11. Fevereiro de 2011.

32 RIBEIRO, Wagner Costa.International environmental order and the emergence of new powers. Fudan Journal of the Humanities and Social Sciences, v. 4, p. 79-92, 2011.

${ }^{33}$ UNITED NATIONS HIGH COMMISSIONER FOR REFUGEES, EXECUTIVE COMMITTEE. Questions and answers on UNHCR's Protection Cluster Coordination role in natural disasters, p. 11. Fevereiro de 2011.
} 
Os direitos humanos foram reconhecidos pela Declaração Universal de Direitos Humanos de 1948, pelo Pacto Internacional de Direitos Civis e Políticos assim como pelo Pacto de Direitos Econômicos Sociais e Culturais, ambos criados em 1966. Mas todos esses Instrumentos têm um caráter geral, pois o destinatário é o ser humano.

Essas Declarações e Pactos poderiam ser aplicados de forma suplementar, pois não estão dirigidos especificamente aos refugiados ambientais.

Em 2007, o Secretário Geral de Nações Unidas designou ao Alto Comissariado de Direitos Humanos e ao Conselho de Direitos Humanos para assumir a competência sobre os Direitos Humanos e os impactos das Mudanças Climáticas. Esses organismos elaboraram uma serie de Resoluções, que reconhecem a violação dos Direitos Humanos dos deslocados ambientais forçados.

Margaretha WEWERINKE enuncia as resoluções que foram criadas pelo Conselho de Direitos Humanos e pelo Alto Comissariado dos Direitos Humanos de Nações Unidas: a Resolução 7/23 do Conselho de Direitos Humanos, a Resolução 10/61 do Alto Comissário dos Direitos Humanos de Nações Unidas, a Resolução 10/4 do Conselho de Direitos Humanos de março 2009, a Reunião de Fevereiro de 2012, a Resolução do Conselho de Direitos Humanos 20/7 de 10 de abril de 2012, a Resolução de 18/22 do Alto Comissariado dos Direitos Humanos de Nações Unidas de setembro de 2012, fevereiro de 2012, onde é criado o cargo de Especialista independente, John Knox. ${ }^{34}$

Todas essas resoluções reconheceram a violação dos direitos humanos pelos impactos das Mudanças Climáticas.

Outro princípio estabelecido pela Reunião de Bellagio foi o Consentimento dos Estados afetados pelos desastres. ${ }^{35}$ Essa Diretriz consiste em que o Estado afetado pelo desastre deve requerer expressamente a ajuda internacional, e expressar seu consentimento para que os organismos possam atuar em seu território. Isto é em respeito aos Princípios Internacionais de Soberania dos Estados e Não Intervenção. ${ }^{36}$

\footnotetext{
${ }^{34}$ WEWERINKE, Margaretha. Climate Change, Human Rights and the International Legal Or der: The Role of the UN Human Rights Council. 4CMR Working Paper Series. Cambridge Centre for Climate Change Mitigation Research (4 CMR). Disponível em: <http://be.4cmr.group.cam.ac.uk/workingpapers/pdf/4CMR_WP_04.pdf> Acesso em: 5 jun. 2014.

35 UNITED NATIONS HIGH COMMISSIONER FOR REFUGEES, EXECUTIVE COMMITTEE. Questions and answers on UNHCR's Protection Cluster Coordination role in natural disasters, p. 11. Fevereiro de 2011.

36 RIBEIRO, Wagner Costa. Soberania: conceito e aplicação para a gestão da água. Scripta Nova. Barcelona, v. XVI, p. 01-11, 2012.
} 
A Participação assegura que seja escutada a voz daqueles que sofrem o processo de degradação ou de desastre, que constituem os principais atores, pois são os que sofrem as violações a seus direitos humanos e sua dignidade. Isto implica que o processo da formação das diretivas que regem a situação da catástrofe emerge de baixo para cima. Deste modo, serão contempladas as principais necessidades os afetados. ${ }^{37}$

A relevância de considerar uma especial proteção aos grupos vulneráveis se deve a que no processo da degradação ou do desastre ocorrido em países em desenvolvimento, se verifica um denominador comum que é a vulnerabilidade. ${ }^{38} \mathrm{~A}$ esta situação se soma a maior vulnerabilidade daquelas pessoas que estão em uma situação de inferioridade diante dos demais afetados, como é o caso das crianças, os idosos, as mulheres e as comunidades tradicionais.

Em junho de 2011 foi realizada a Conferência Nansen, cujo tema era as mudanças climáticas e os deslocamentos ambientais, na qual participaram 240 acadêmicos de diversos países do mundo. Nessa reunião foram elaborados os dez princípios que orientam a questão dos deslocamentos e as mudanças climáticas. Esses princípios fazem referência aos aspectos fundamentais que devem ser observados pelos Estados e pelos Organismos Internacionais em relação aos deslocados ambientais forçados. Em primeiro lugar, se considera que soluções devem estar fundadas no aporte da ciência e "nos princípios de humanidade, dignidade, direitos humanos, cooperação internacional [...] não discriminação, consentimento e participação. ” Também, se estabelece que é necessário brindar uma especial proteção aos grupos vulneráveis. Por outro lado, se reconhece a responsabilidade do Estado nacional perante a situação de emergência e dos deslocamentos internos. Caso esse país não consiga fazer frente à situação do Desastre e dos deslocamentos, será implementada a Ajuda Internacional, desde que com prévio consentimento do país de origem. A Assistência Internacional buscará o desenvolvimento das capacidades nacionais. A necessidade de que seja criado um Marco de Referencia Global sobre a proteção dos Deslocados Ambientais Forçados, assim como a necessidade de que ACNUR participe na elaboração desse quadro normativo surge dos princípios $n^{\circ}$ VII e IX. O princípio $n^{\circ}$ VII reconhece a necessidade de que sejam abordadas a lacunas normativas sobre os deslocados ambientais forçados. O princípio IX considera que é necessário “o mais coerente enfoque a nível

\footnotetext{
${ }^{37}$ UNITED NATIONS HIGH COMMISSIONER FOR REFUGEES, EXECUTIVE COMMITTEE. Questions and answers on UNHCR's Protection Cluster Coordination role in natural disasters, p. 11. Fevereiro de 2011.

${ }^{38}$ ZANIRATO, Silvia H.; Ribeiro, Wagner Costa. Mudanças climáticas e risco ao patrimônio cultural em Ouro Preto ? MG - Brasil. Confins - revue franco-brésilienne de géographie, v. 21, p. 1-20, 2014.
} 


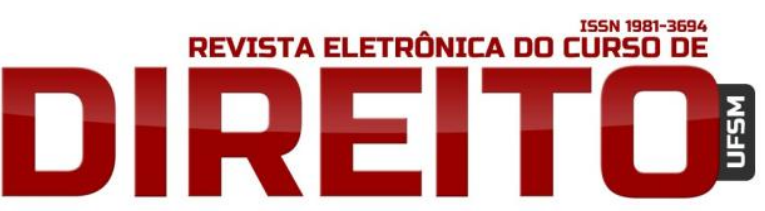

REFUGIADOS AMBIENTAIS E A ATUACC̃O DO ACNUR COMO ORGANISMO INTERNACIONAL DE PROTEÇÃO

MARIA DE LAS MERCEDES RODRÍGUEZ FONTÁN LUCHINO WAGNER COSTA RIBEIRO

internacional é necessário para satisfazer a proteção de uma guia marco ou instrumento ao respeito."39

A gênese desses princípios pode ser encontrada na Reunião de Bellagio, que já foi previamente considerada.

\subsubsection{O plano piloto do IASC para que o ACNUR fosse o líder na proteção dos Deslocados Ambientais Forçados}

Depois das reiteradas manifestações do ACNUR em relação a sua capacidade de assumir a proteção destes deslocados forçados, e das diversas respostas lideradas por este organismo diante dos deslocamentos dos desastres, o Alto Comissariado mantinha a esperança de que, finalmente, assumiria essa responsabilidade frente aos deslocados ambientais forçados.

Segundo a reforma de 2005 do Sistema de Ajuda Humanitária das Nações Unidas para fazer frente aos desastres naturais e das emergências complexas, existiam três agências internacionais que poderiam ser líderes na resposta à proteção dos deslocados ambientais. 0 processo de escolha do líder do grupo fazia com que a resposta fosse demorada, causando grandes prejuízos às vitimas. Desse modo, em inícios de 2011, o IASC elaborou um plano piloto, no qual o ACNUR se encarregaria da liderança do grupo de proteção dos deslocados dos desastres naturais. ${ }^{40}$

O Plano Piloto de IASC considerava o problema dos atrasos na eleição do organismo internacional que lideraria a resposta à emergência e ao desastre. A proposta era que o ACNUR assumisse essa liderança pelo período de um ano. Esse órgão já havia atuado como líder do grupo de proteção dos deslocados dos desastres naturais, baseando-se no mecanismo dos "bons ofícios". ${ }^{41}$

\footnotetext{
${ }^{39}$ KALIN, Walter. From the Nansen Principles to the Nansen Initiative. FMR 41, p. 48. Disponível em: <http://www.fmreview.org/preventing/kalin>. Acesso em: 15 jan. 2014.

40 EXECUTIVE COMMITTEE OF THE HIGH COMMISSIONER'S PROGRAMME STANDING COMMITTEE. 51st meeting. EC/62/SC/CRP.19. 6 de Junho de 2011, parágrafos 1 a 4.

${ }^{41}$ UNITED NATIONS HIGH COMMISSIONER FOR REFUGEES, Executive Committee. Questions and answers on UNHCR's Protection Cluster Coordination role in natural disasters. Fevereiro de 2011, paragrafo 4.
} 
Especificamente, os desastres naturais mais importantes nos quais o ACNUR interveio foram: o tsunami de 2004, “Paquistão (2010, inundações), Filipinas (2009, inundações), Myanmar (2008, Ciclone Nargis) e Sri Lanka (2004, tsunami)", e Haiti. ${ }^{42}$

O conceito estabelecido na reforma de 2005 do IASC de "Líder de Grupo de Proteção" fazia referência: "às responsabilidades para a coordenação, gestão da informação, da planificação estratégica [...] atuando no contexto interinstitucional como a agencia de 'provedor de último recurso '."43

ACNUR foi criado para proteger aos refugiados e é encarregado da proteção dos deslocados internos, como já foi observado anteriormente. Os problemas concretos sofridos pelos deslocados internos derivados dos conflitos internos armados e por desastres, e dos refugiados estatutários (os que foram deslocados por razões políticas) são muito similares aos deslocados forçados ambientais.

Tais situações são: o perigo contra a vida, "perda de documentação, de moradia, da terra e da propriedade, do acesso à informação e aos serviços básicos”, assim como a necessidade de proteção especial aos grupos vulneráveis como "as crianças que foram separadas de suas famílias, as mulheres, e as meninas expostas à violência sexual e de gênero, pessoas com incapacidades e os idosos."44

Essas circunstâncias constituem violações aos direitos humanos de todos esses grupos de Deslocados Ambientais Forçados.

Estas questões estão previstas no Estatuto do Refugiado, nos Princípios Reitores dos Deslocados Internos, ainda que estes regimes jurídicos somente amparem os refugiados estatutários e os deslocados internos (incluindo os dos desastres naturais), deixando desprotegidos os deslocados ambientais forçados que atravessam as fronteiras.

A Proposta do IASC para que o ACNUR fosse encarregado da liderança do grupo de proteção dos deslocados dos desastres naturais foi realizada na Reunião dos Delegados dos países membros do ACNUR, celebrada no mês de junho de 2011. A maioria dos Delegados dos países participou do debate e em princípio eles expressaram seu apoio, apesar de que houve muitas objeções. Finalmente, eles concluíram pela rejeição da proposta. As principais objeções foram:

\footnotetext{
42 EXECUTIVE COMMITTEE OF THE HIGH COMMISSIONER'S PROGRAMME STANDING COMMITTEE. 51st meeting. EC/62/SC/CRP.19. 6 de Junho de 2011, par. 9.

${ }^{43}$ UNITED NATIONS HIGH COMMISSIONER FOR REFUGEES, Executive Committee. Questions and answers on UNHCR's Protection Cluster Coordination role in natural disasters, paragrafo 10. Febrero de 2011.

${ }^{44}$ UNITED NATIONS HIGH COMMISSIONER FOR REFUGEES, EXECUTIVE COMMITTEE. Questions and answers on UNHCR's Protection Cluster Coordination role in natural disasters, par. 11. Fevereiro de 2011.
} 
a questão da soberania, os recursos econômicos destinados ao atendimento dessas novas atividades, as repercussões que isso teria sobre o mandato central, o problema da saída do país afetado, a necessidade de maiores informações sobre a questão e a necessidade de que a questão fosse introduzida por uma Resolução da Assembleia Geral das Nações Unidas. ${ }^{45}$

A rejeição da proposta constituiu um golpe muito forte e inesperado para o ACNUR, que pensava que obteria o apoio das Delegações.

\section{OBSERVAÇÕES SOBRE O ACNUR DE 2013 A 2014}

Em Genebra, em 23 de fevereiro de 2013, foi celebrado o "Seminário sobre os impactos adversos e o desfrute dos Direitos Humanos", no qual foram apresentadas observações sobre os deslocados ambientais "externos". De um lado, considerou-se o aspecto positivo referente à participação do Conselho de Direitos Humanos de Nações Unidas, as declarações e os pactos internacionais de Direitos Humanos assim como o reconhecimento de Convenção- Quadro das Nações Unidas sobre Mudanças Climáticas (UNFCCC) de Cancun, em 2010. Por outro lado, observou-se a falta de atuação em relação ao problema da ausência de proteção dos deslocados ambientais "externos". Também foram feitas observações sobre a realocação dessas pessoas. ${ }^{46}$

Em fevereiro de 2014, o ACNUR apresentou as Diretrizes sobre as Medidas de Proteção Temporal. Estas medidas precisam ser desenvolvidas por cada país, para fazer frente aos deslocados forçados da emergência humanitária, "particularmente em situações onde as respostas existentes não são adequadas"47. Estes Princípios Orientadores estabelecem os aspectos essenciais que devem ser contemplados. O Guia de Proteção Temporária (TPSA) ${ }^{48}$ considera o momento de ingresso no país, a estadia e a solução final da situação. Em relação ao primeiro estágio, reconhece os direitos à entrada no país, o acesso à documentação, e que sejam satisfeitas as situações derivadas da emergência como a falta de alimentos, água, saúde,

45 EXECUTIVE COMMITTEE OF THE HIGH COMMISSIONER'S PROGRAMME STANDING COMMITTEE. 52nd meeting. Draft Report of the 51st meeting of the Standing Committee (21-23 June 2011). EC/62/SC/CRP.25, parágrafos 30, 32 y 33. 16 de setembro de 2011.

${ }_{46}$ UNHCR, Headquarters. Seminar to Address the Adverse Impacts of Climate Change on the Full Enjoyment of Human Rights Session 2: International Cooperation and Respect for Human Rights (Remarks of Mr. José Riera Senior Adviser Division of International Protection). 23 February 2013, Palais des Nations, Salle XII. Disponível em: <http://www.unhcr.org/543e77a19.html> Acesso em: 14 out. 2015.

${ }_{47}$ UNHCR. DIVISION OF INTERNATIONAL PROTECTION. Guidelines on Temporary Protection or Stay Arrangements. Febrero, 2014, p. 4 y 5. Disponível em: <http://www.unhcr.org/542e99fd9.html>. Acesso em: 14 out. 2015.

${ }^{48}$ TPSA significa Temporary Protection or Stay Arrangements. 
moradia, roupa e unidade familiar. Nessa etapa inicial é fundamental que seja realizado o cadastramento das pessoas afetadas para melhorar o reconhecimento. 0 registro desses deslocados forçados poderia considerar os aspectos particulares da situação que aflige esses grupos ou indivíduos. Isto permitiria que fosse oferecido tratamento para tais danificados. Além disso, são considerados os direitos mínimos assegurados para essas pessoas, os quais consistem em que thes seja garantida uma vida digna. Isto implica os direitos a moradia adequada (assegurando-lhes o acesso à água potável e serviços sanitários), saúde, alimentos, educação, trabalho, o direito à documentação necessária, o direito à liberdade de circulação, o direito à segurança, unidade familiar, que the sejam oferecidos os meios para localizar os parentes desaparecidos e proteção para as crianças e os incapacitados. ${ }^{49}$

Em março de 2014, o ACNUR convocou uma reunião em San Remo, com a participação de duas instituições, Brookings Institution e Georgetown University's Institute for the Study of International Migration (ISIM), onde se iniciou a discussão sobre "adaptação, desenvolvimento dos deslocamentos induzidos e reassentamento, gestão do risco de desastres, proteção civil, meio ambiente e mudanças climáticas, à assistência humanitária e direitos humanos". ${ }^{50}$

Em 05 de junho de 2014, em Bonn, a Universidade das Nações Unidas e a Iniciativa Nansen elaboraram um trabalho que foi apresentado, no qual forma considerados os impactos negativos das mudanças climáticas e dos deslocamentos forçados. Nesse estudo se reconhece que os países precisam incorporar os deslocamentos forçados das mudanças climáticas a seus Planos Nacionais de Adaptação (PNA). Este informe observa o caso de Kiribati, um país insular que realizou tal incorporação a seu Plano de Adaptação Nacional, dando educação a seus nacionais para que tivessem as condições de afrontar o mercado internacional. Hannah Entwisle Cahpuisat, pesquisadora oficial da Iniciativa Nansen, observou que "É crucial que os países desenvolvam as medidas centradas na prevenção do deslocamento quando seja possível, proporcionando oportunidades positivas para adaptação como a migração voluntária ou realocação planificada". ${ }^{51}$

\footnotetext{
49 UNHCR. DIVISION OF INTERNATIONAL PROTECTION. Guidelines on Temporary Protection or Stay Arrangements. Febrero, 2014, p. 4 y 5. Disponivel em: <http://www.unhcr.org/542e99fd9.html>. Acesso em: 14 out. 2015.

50 UNHCR. Unhcr, The Environment \& Climate Change. UPDATED VERSION, October 2015, p. 11. Disponível em: <http://www.unhcr.org/540854f49.pdf> Acesso em: 2 dez. 2015.

51 INICIATIVA NANSEN. Human mobility and climate change adaptation: UN University and Nansen Initiative present new policy brief, 5 de Junio de 2014, p. 1. Disponível em: <https://www.nanseninitiative.org/human-mobility-and-climate-change-adaptation-un-university-andnansen-initiative-present-new-policy-brief> Acesso em: 14 out. 2015.
} 
Em junho de 2014, Koko Warner, Chefe da Secção de Migração Ambiental, Vulnerabilidade Social e Adaptação em UNU-EHS alerta que:

Muitas pessoas em todo o mundo, como as que lutam contra o aumento do nível do mar nos Estados Insulares do Pacífico e as que lutam contra as secas persistentes e cada vez mais intensas no Chifre da África, são obrigadas a mobilizar-se e já não se trata de uma realidade distante, é a realidade. ${ }^{52}$

São considerados alguns fatos relacionados com a atualização do ACNUR sobre os deslocados forçados ambientais:

Uma reunião de expertos foi celebrada em Washington em 13 de fevereiro de 2015 para celebrar especificamente nas definições da terminologia. A Instituição Brookings, em colaboração com o ACNUR e o Instituto da Universidade de Georgetown para o Estudo da Migração Internacional (ISIM), convocou uma pequena consulta de expertos em Bellagio, Itália, no mês de junho de 2015 para desenvolver novas orientações para os governos na realização de traslados previstos nos contextos das mudanças climáticas e dos desastres. 0 guia foi publicado em 7 de outubro de 2015. ${ }^{53}$

Por outro lado, em Bellagio, em maio de 2015, começou-se a tratar a Realocação Planificada ou Reassentamento. Em outubro de 2015 foi apresentado o Guia sobre a Realocação Planificada para os deslocados ambientais forçados. ${ }^{54}$

Em outubro de 2015, o ACNUR apresentou sua mais atual publicação, "UNHCR, The Enviromental \& Climate Change”, a que revela que há 59,5 milhões de pessoas que vivem nas regiões mais vulneráveis aos desastres. Além disso, observa que:

O ACNUR desempenhou um papel importante na proteção das populações afetadas por, entre outras, as secas na Somália em 2011 e 2012, as inundações no Paquistão entre 2010 e 2012, as tempestades e as inundações em Myanmar em 2013, e os tufões nas Filipinas (Washi- Sendong em 2011-2012 e Hayan- Yolanda em 2013) vítimas do ciclone e das inundações. [...]

Mais recentemente, em 2015, o ACNUR prestou assistência em Myanmar, nos estados de Rakhine e Kachin, as vitimas do devastador terremoto assistidas no Nepal e a realocação de 50.000 refugiados afetados pelas inundações na Etiópia. [...] A título de exemplo, o ACNUR alcançou quase meio milhão de sobreviventes do tufão Haiyan (Filipinas, 2013) com subministros vitais. O ACNUR segue

\footnotetext{
52 INICIATIVA NANSEN. Human mobility and climate change adaptation: UN University and Nansen Initiative present new policy brief. 5 de Junho de 2014. Disponível em: <https://www.nanseninitiative.org/human-mobility-and-climate-change-adaptation-un-university-andnansen-initiative-present-new-policy-brief> Acesso em: 14 de out. 2015.

53 UNHCR. Unhcr, The Environment \& Climate Change. UPDATED VERSION, October 2015, p. 11. Disponível em: <http://www.unhcr.org/540854f49.pdf> Acesso em 2 dez. 2015.

${ }^{54}$ UNHCR. Unhcr, The Environment \& Climate Change. UPDATED VERSION, October 2015, p. 10 e 11. Disponível em: <http://www.unhcr.org/540854f49.pdf> Acesso em 2 dez. 2015.
} 
prestando assistência aos sobreviventes mais vulneráveis do tufão, em particular, os povos indígenas como os Badjão. ${ }^{55}$

Dessa forma, é necessário reconhecer que o ACNUR atuou oferecendo ajuda aos deslocados ambientais forçados nos anos de 2010, 2011, 2012, 2013 e em 2014.

\section{CONCLUSÃO}

Em primeiro lugar, é preciso apontar que existe a necessidade de que seja instituída uma regulação internacional para proteger os deslocados ambientais forçados, independentemente de atravessar as fronteiras ou não, pois constituem uma figura única, como foi considerado na construção da definição apontada nesse texto.

Em segundo lugar, pode-se observar que a pior situação é a vivida pelos deslocados ambientais forçados "externos", os quais estão totalmente desprotegidos diante do direito internacional, e não tem a proteção nem de seus países de origem, nem do país de destino. Enquanto os deslocados ambientais forçados internos estão amparados pelos Princípios Orientadores dos Deslocados Internos e o organismo que os protege é o ACNUR, os externos ou que escapam as fronteiras estão desprovidos de apoio institucional.

Os dados referentes ao número crescente de deslocados ambientais forçados são alarmantes. O organismo que poderia se encarregar dos deslocados ambientais forçados "externos" seria o ACNUR, dado o que foi demonstrado por sua experiência desenvolvida desde 1951 com refugiados. Além disso, o ACNUR é responsável pelos deslocados internos dos desastres naturais, o que demonstra sua capacidade em relação à questão.

$\mathrm{Na}$ ordem ambiental internacional, é crescente o número de organismos que atuam na questão, seja por meio de atividades de investigação, da criação de políticas e da busca de consensos como demonstrado pela Iniciativa Nansen.

Desde 2007, o ACNUR mudou sua posição de paralisia perante a problemática dos deslocados ambientais forçados externos. O Secretário Geral das Nações Unidas demonstrou interesse pela questão criando grupos para analisar o problema. Por outro lado, o IACS também organizou o sistema de assistência na emergência e desastres naturais. Outro ator da ordem ambiental internacional que atuou foi a Conferência das partes da UNFCCC de 2010, que em sua

\footnotetext{
${ }^{55}$ UNHCR. Unhcr, The Environment \& Climate Change. UPDATED VERSION, October 2015, p. 9. Disponível em: <http://www.unhcr.org/540854f49.pdf>. Acesso em: 2 dez. 2015.
} 
resolução apontou que os países desenvolvidos deverão ajudar aos migrantes induzidos pelas mudanças climáticas, pela primeira vez trazida para a esfera internacional, o que permite reivindicar verbas do Fundo Verde para as Mudanças Climáticas da UNFCCC.

Por outro lado, o ACNUR realizou vários eventos para tentar elaborar um consenso sobre os deslocados ambientais forçados externos, tais como as diversas reuniões de Bellagio. Já o IACS propôs que o ACNUR coordenasse os trabalhos, que foram, ao final, rejeitados pelos delegados dos países. Também cabe destacar que o ACNUR atuou nos casos de assistência a diversos países em situação de desastres por meio do Mecanismo de Bons Ofícios.

A análise da atuação de ACNUR no período que vai de 2007 a 2014 permite verificar que esse organismo tem interesse em assumir a responsabilidade de proteção dos deslocados ambientais forçados.

\section{REFERÊNCIAS}

BIERMANN, Frank; BOAS, Ingrid. Preparing for a Warmer World: Towards a Global Governance System to Protect Climate Refugees. 10 Global Governance Working Paper, N. 33, November 2007, Ámsterdam. Disponível em:<http://www.environmentalmigration.iom.int/preparingwarmer-world-towards-global-governance-system-protect-climate-refugees> Acesso em: 15 fev. 2014.

CLARKE, Meghan Elisabeth. Climate Change and Human Rights: A Case Study of the Canadian Inuit and Global Warming in the Canadian Arctic. A thesis submitted in conformity with the requirements for the degree of Master of Laws (LLM). Graduate Department of the Faculty of Law University of Toronto, Toronto, 2010. Disponível em: <https: //tspace.library.utoronto.ca/ bitstream/1807/25457/1/Clarke_Meghan_E_201011_LLM_thesis.pdf >. Acesso em: 10 jul. 2014.

COP (CANCUN). Decision 1/CP.16, The Cancun Agreements: Outcome of the work of the Ad Hoc Working Group on Long-Term Cooperative Action under the Convention, in Report of the Conference of the Parties on its sixteenth session, Addendum, Part Two: Action taken by the Conference of the Parties, FCCC/CP/2010/7/Add.1, 15 mar. de 2011, parag. 14 (f).

DOCHERTY, Bonnie; GIANNINI, Tyler. Confronting a Rising Tide: A Proposal for a Convention on Climate Change Refugees, 33 Harv. Envtl. L. Rev. 344, 2009. Disponível em: <http: / / lawlib. wlu.edu/CLJC/index.aspx?mainid=244\&issuedate=2009-07-30 . Acesso em: 25 maio 2014.

EL-HINNAWI, Essam. Environmental Refugees. Nairóbi, Kenya: United Nations Environment Programme, 1985. 




REFUGIADOS AMBIENTAIS E A ATUAÇ̃̃O DO ACNUR COMO ORGANISMO INTERNACIONAL DE PROTEÇÃO

MARIA DE LAS MERCEDES RODRÍGUEZ FONTÁN LUCHINO WAGNER COSTA RIBEIRO

EXECUTIVE COMMITTEE OF THE HIGH COMMISSIONER'S PROGRAMME STANDING COMMITTEE. 51st meeting. EC/62/SC/CRP.19. 6 de jun. 2011.

EXECUTIVE COMMITTEE OF THE HIGH COMMISSIONER'S PROGRAMME STANDING COMMITTEE. 52nd meeting. Draft Report of the 51st meeting of the Standing Committee (21-23 June 2011). EC/62/SC/CRP.25. 16 set. 2011.

GUTERRES, António. Five 'mega-trends'-including population growth, urbanization, climate change-make contemporary displacement increasingly complex, third committee told, Third Committee, General Assembly GA/SHC/3964, New York: United Nations, 3 November 2009. Disponível em: <http://www.un.org/press/en/2009/gashc3964.doc.htm> Acesso em: 2 jan. 2014.

HALL, Nina. Moving beyond Its Mandate? UNHCR and Climate Change Displacement. 4 Journal of Int'l Orgs Studies, 2013.

HODGKINSON David and YOUNG, Lucy. "In the face of looming catastrophe": A Convention for Climate Change Displaced Persons, 2009. Disponível em: <http://www.ccdpconvention.com/ documents / A\%20Convention\%20for\%20Climate\%20Change\%20Displaced\%20Persons\%20\%28January \%202012\%29.pdf> Acesso em: 20 fev. 2014.

IASC. Directrices operacionales del IASC sobre la protección de las personas en situaciones de desastres naturales. Proyecto de Brookings - Bern sobre Desplazamiento Interno, maio de 2011. Disponível em: <http://www. hewsweb.org/floods/flood.asp?FID=198379>. Acesso em: 20 jul. 2014.

INTERNAL DISPLACEMENT MONITORING CENTER. NORWEGIAN REFUGEE COUNCIL. People displaced by disasters. Global Estimatives 2015, 2015.

INTERNAL DISPLACEMENT MONITORING CENTER. NORWEGIAN REFUGEE COUNCIL. People displaced by disasters. Global Estimatives 2014, 2014.

KALIN, Walter. From the Nansen Principles to the Nansen Initiative. FMR 41, December 2012. Disponível em: <http://www.fmreview.org/preventing/kalin>. Acesso em: 15 jan. 2014.

KÄLIN, Walter; SCHREPFER, Nina. Protecting People Crossing Borders in the Context of Climate Change Normative Gaps and Possible Approaches. University of Bern, UNHCR, Switzerland, 2012. Disponível em: <http://www.unhcr.org/4f33f1729.pdf>. Acesso em: 15 jan. de 2014.

MAYER, Benoit. The International Legal Challenges of Climate-Induced Migration: Proposal for an International Legal Framework, 22 COLO. J. INT'L ENVTL. L. \& POL'Y 357, 366 (2011), p. 368 e 369.

MC ADAM, Jane. Creating New Norms on Climate Change, Natural Disasters and Displacement: International Developments 2010-2013. Refugee, Vol. 29, No 2, 2014. Disponível em:

<http://www.unhcr.org/542e9a509.pdf >. Acesso em: 15 jun. 2015. 
NANSEN INICIATIVE. Linking human mobility, disasters and disaster risk reduction, outubro de 2014. Disponible em: <http://www.unhcr.org/5448c8269.html>. Acesso em: 15 jun. 2015.

RIBEIRO, Wagner Costa. Soberania: conceito e aplicação para a gestão da água. Scripta Nova (Barcelona), v. XVI, p. 01-11, 2012.

. International environmental order and the emergence of new powers. Fudan Journal of the Humanities and Social Sciences, v. 4, p. 79-92, 2011.

. A ordem ambiental internacional. São Paulo: Contexto, 2001.

RODRIGUEZ FONTÁN LUCHINO, María de las Mercedes. Los Desplazados Ambientales Forzados y la violación de sus derechos humanos. In: Anales del II Congreso Internacional SETED-Ante, Universidad de Santiago de Compostela. España, 2015.

RODRIGUEZ FONTÁN LUCHINO, María de las Mercedes. La Pérdida del territorio de los Pequeños Estados Insulares. In: Anais do XI Encontro Nacional da Anpege: A diversidade da Geografia Brasileira -Escalas e dimensões da análise e da ação. Presidente Prudente: ANPEGE-UNESP, 2015.

UNHCR. Climate change, natural disasters and human displacement: a UNHCR perspective. Publicado por UNHCR, Genebra, October, 2008. Disponível em: <http://www.unhcr.org/ 4901e81a4.html>. Acesso em: 10 jan. 2014.

UNITED NATIONS HIGH COMMISSIONER FOR REFUGEES. POLICY DEVELOPMENT AND EVALUATION SERVICE (PDES). Earth, wind and fire. A review of UNHCR"s role in recent natural disasters. Bryan Deschamp, Consultant. Michelle Azorbo, PDES. Sebastian Lohse, Consultant. PDES, jun. de 2010.

UNITED NATIONS HIGH COMMISSIONER FOR REFUGEES, EXECUTIVE COMMITTEE. Questions and answers on UNHCR's Protection Cluster Coordination role in natural disasters. Fevereiro de 2011.

UNHCR Headquarters. Seminar to Address the Adverse Impacts of Climate Change on the Full Enjoyment of Human Rights Session 2: International Cooperation and Respect for Human Rights (Remarks of Mr. José Riera Senior Adviser Division of International Protection), 23 February 2013, Palais des Nations, Salle XII.

UNHCR. DIVISION OF INTERNATIONAL PROTECTION. Guidelines on Temporary Protection or Stay Arrangements. Febrero, 2014. Disponível em: <http://www.unhcr.org/542e99fd9.html> Acesso em:21 out. 2015.

UNHCR. Unhcr, The Environment \& Climate Change. Updated Version, Outubro 2015.Disponível em: <http://www.unhcr.org/540854f49.pdf>. Acesso em: 2 dez. 2015.

WARNER, Koko. Environmental Change and Migration: Issues for European governance and migration management. Network Migration In Europe E.V. Disponível em

<www.migrationeducation.org>. Acesso em: 20 mar. 2014. 
ISSN 1981-3694

(DOI): $10.5902 / 1981369422071$

REVISTA ELETRÔNICA DO CURSD DE

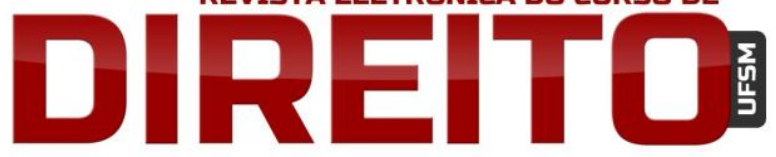

REFUGIADOS AMBIENTAIS E A ATUAÇÃO DO ACNUR COMO ORGANISMO INTERNACIONAL DE PROTEÇÃO

MARIA DE LAS MERCEDES RODRÍGUEZ FONTÁN LUCHINO WAGNER COSTA RIBEIRO

WEWERINKE, Margaretha. Climate Change, Human Rights and the International Legal Or der: The Role of the UN Human Rights Council. 4CMR Working Paper Series. Cambridge Centre for Climate Change Mitigation Research (4 CMR). Disponível em:

<http://be.4cmr.group.cam.ac.uk/working-papers/pdf/4CMR_WP_04.pdf>Acesso em: 5 jun. 2014.

ZANIRATO, Silvia H.; RIBEIRO, Wagner Costa. Mudanças climáticas e risco ao patrimônio cultural em Ouro Preto? MG - Brasil. Confins - revue franco-brésilienne de géographie, v. 21, p. 1-20, 2014.

Recebido em: 02/05/2016 / Revisões requeridas em:16/08/2016 / Aprovado em: 26/10/2016 